\title{
From a Different Place to a Third Space: Rethinking International Student Pedagogy in the Western Conservatoire
}

\author{
Biranda Ford
}

\begin{abstract}
Conservatoires in the West are now made up of a significant body of international students who come to study the Western canon of classical music. With the canon arising in the same milieu as Enlightenment notions of shared humanity, historically, many have argued that this music has a wide, cross-cultural appeal. Though such tropes of classical music still exist, they also have the potential today to act as awkward anachronisms, markers of elitism, whiteness and cultural hegemony. This chapter starts from the perspective that the considerable economic contribution of international students to host institutions risks reproducing colonial relations if their pedagogical experiences are not thought through carefully. Looking to postcolonial theory to make sense of the dynamics at play, key concepts from Homi Bhabha are used as a lens to view the conservatoire. It is argued that international students are marginalized through stereotyping and positioned 'in need' of a Western education, even with attempts to bring their cultural experience of learning into account. I advocate that the conservatoire must move beyond its attempts to contain the effects of cultural diversity and instead harness the potential for self-renewal that comes from embracing cultural difference in a third space.
\end{abstract}

Keywords Western classical music - Music higher education - Conservatoires · Music pedagogy $\cdot$ International students $\cdot$ Cultural difference $\cdot$ Music education research · Intercultural education · Postcolonial theory $\cdot$ Third space

\footnotetext{
B. Ford $(\bowtie)$

Guildhall School of Music \& Drama, London, UK

e-mail: biranda.ford@gsmd.ac.uk

(C) The Author(s) 2021

A. A. Kallio et al. (eds.), The Politics of Diversity in Music Education, 


\section{Introduction}

Conservatoires in the West, within the contemporary context of a globalized market for higher education, are now made up of a significant body of international students. ${ }^{1}$ Though the increased mobility of students worldwide is a relatively new phenomenon, conservatoires have long supported an international body of faculty and students who come together to learn and teach the Western canon of classical music. With the canon arising in the same milieu as Enlightenment notions of shared humanity - for instance, Kantian cosmopolitanism - historically, many have argued that this music has a wide cross-cultural appeal. In the nineteenth century, the century of the founding of many of Europe's prestigious conservatoires (Ford 2010), much was written about music's ability to transcend language barriers or to function as a fundamental pre-language speaking to universal emotions and direct human experience (for instance, Schopenhauer 1818). Though such tropes of classical music still have currency - witness Daniel Barenboim's references to classical music as 'international language' (2016) - they also have the potential to be read as awkward anachronisms, markers of elitism, whiteness and cultural hegemony as today's identity politics negate any appeal to universal experience. So how might we understand what happens when Western classical music is taught to international students in the contemporary conservatoire?

This chapter starts from the perspective that the considerable economic contribution of international students to host institutions risks reproducing colonial relations if their pedagogical experiences are not thought through carefully. Looking to postcolonial theory to make sense of the dynamics at play, I use key concepts from Homi Bhabha (1994) as a lens to view the conservatoire. Concepts such as Bhabha's 'hybridity' - that peoples and cultures no matter where they seem to originate are always irreducibly hybrid - and 'the third space', a notional site that enables students to negotiate and reimagine different hybrid identities, are considered in terms of current and suggested future conservatoire practices. More specifically, I argue that international students are marginalized through stereotyping and positioned 'in need' of a Western education, even with attempts to bring their cultural experience of learning into account. I advocate that the conservatoire must move beyond its attempts to contain the effects of cultural diversity and instead harness the potential for self-renewal that comes from embracing cultural difference in a third space. Though I speak primarily from my UK location, I bring in literature also from Australia and the USA, in the hope that my observations will be applicable to other settings.

\footnotetext{
${ }^{1}$ Here, 'West' or 'Western' denotes Europe and Northern America and also countries that are English speaking and draw substantially on Europe for political, social, cultural and educational traditions, for example, Australia. I use the word 'conservatoire' here to mean schools of music in higher education, either independent institutions or within university music departments, that focus on the tuition of Western classical music performance.
} 


\section{The Economic Imperative of Internationalism in Higher Education}

The higher education market in the UK is increasingly reliant on international students. By 2017 the contribution to the overall economy by international students was in excess of $£ 25$ billion (Universities UK 2017). Though the need to recruit internationally to the UK has existed since cuts were made to government funding in the 1980s, where once a significant number of students came from the European Union, repeated financial crises in the Eurozone from 2008 onwards have resulted in an increased dependence on non-Western students. Reporting in 2017, the Higher Education Statistics Agency noted that students from China had outnumbered students from all EU countries since 2012, amounting to one fifth of the entire international student population. Though non-EU students have always paid a premium in fees over their EU counterparts, the now uncertain future of Britain in the EU is predicted to further increase higher education's reliance on overseas markets.

For British conservatoires, 'overseas markets' primarily means East Asia. Staff embark on annual recruitment circuits in cities across China, Taiwan, Japan, Singapore and neighbouring countries, and conservatoire website information can be found translated into Mandarin and Japanese. Whilst this geographical concentration builds upon the historic popularity of classical music in the region, where once Japanese and Korean students came to study in British conservatoires, they are joined by Chinese students who are now a dominant force in classical music studies across the world.

Based on press reports in the UK and the USA that cite up to 40 million children across China playing the piano and 50 million the violin, Huang (2012) has presented numerous commentators' predictions that China could overtake Western countries in their expertise in classical music. This is perhaps evidence of the success of the Chinese government's endorsement of classical music at the highest political levels, an endorsement which has also triggered the mass building of concert halls and opera houses in recent years. In stark contrast to the banning of classical music under Mao at the time of the Cultural Revolution for exemplifying Western bourgeois values, it would seem that classical music in China has been officially realigned with traditional Confucian values such as discipline and hard work (Huang 2012). This points to another distinguishing feature of the classical music boom in China, namely, that it has not required the suppression of its own traditional music or cultural values. Whilst the Japanese favoured Western classical music over its own musical traditions (Schippers 2010), the Chinese interest in Western music has taken place alongside a proud promotion of its own. For instance, Chinese traditional song is used in school education to inculcate a strong sense of national heritage and identity (Ho 2018). Huang (2012) does suggest that Western classical music taps into a contemporary Chinese need to demonstrate its superiority and modernity to the rest of the world by excelling at Western cultural traditions. However, that this takes place alongside the championing of its own music could 
suggest also an embracing of plurality rather than an overriding impulse to respond to past Western colonial domination.

In this light, the decision to study in Britain and other Western conservatoires by Chinese students would seem to involve the matching of existing teaching expertise with a growing demand for tuition. Those who justify internationalism in higher education as an efficient way of providing skills for students around the world to become workers in a global economy would perhaps see this as a happy meeting of consumer and provider. The teaching of a common repertoire and musical values to all students, home and international, who have enrolled by choice and who might notionally compete for the same orchestral positions across the world, might appear to be a reasonable approach to take. However, is this education as neutral an endeavour as this argument would suggest? Can the discourse of a global workforce prepared by an international education dispel a modern distrust of universalizing explanations?

A formative experience in my own journey into this topic was the informal conversations with students and teachers that alerted me to the fact that international student education - so common in the conservatoire world as to be invisible - might not be as unproblematic as it might seem. In tertiary music education institutions in the UK, Belgium and USA, I have heard strikingly similar accounts of how Chinese and other East Asian students as musicians are seen through the eyes and ears of those brought up through the Western classical music system. Stories of 'excellent technique' and 'amazing sound' but a lack of 'true' musical understanding, or 'shallow' readings, have been voiced, along with assertions that European composers base their instrumental music on their mother tongue, therefore rendering those that come from other language traditions unable to access the full implications of 'the composer's intentions' (see Wang 2019). These comments would suggest that classical music's universal status in its performance, reception and teaching is not as straightforward as it might at first seem. In addition, if students who do not match up to Western norms might be placed at a disadvantage, then we ought to take a closer look to untangle the complexity at play.

\section{Conservatoires: Evading Four Decades of Debate on Cultural Diversity}

Despite their history of internationalism, conservatoires, whether independent institutions or embedded in university music departments, have not normally been known as sites of cultural diversity. In terms of their core curriculum offerings of a music education based on the Western European canon of classical music, many have successfully resisted a fundamental change in the repertoire they teach and the master-apprentice pedagogy by which it is taught. Long-standing challenges to the authority of the canon, through showing the sociocultural construction of the standard repertory (for instance, Goehr 1992; Citron 1993) or through raising 
awareness of the variety of musical practices that take place across every human culture, have made little change to contemporary mainstream conservatoire practice. For instance, in Britain, whilst contemporary music, jazz, music theatre and national folk musics have made it onto selected courses either as elective choices or as degree programmes in their own right, these additions are notable for staying within familiar Western genres. ${ }^{2}$

That Western musics have been the focus of Western curricula has been problematized extensively in the field of music education. Over four decades, multiple calls for more diverse curricula roughly fit into two categories: (1) the musical, that there are a host of benefits to musicianship from studying a range of musical traditions, and (2) the social - that social justice through cultural representation or that understanding and tolerance of people from other cultures arises from learning other musics (Drummond 2005). These debates have effected a profound change in school music curricula which now include different world musics and varied genres from popular culture as part of their mainstream offering. Though all of these debates are directly applicable to specialist higher education, with a few notable exceptions (for instance, Sydney Conservatorium's Balinese gamelan and Chinese orchestra programmes or the Glomas network's support of intercultural projects across partner institutions), conservatoires have remained largely unaware of the need to engage with these direct critiques either in theory or in practice (Lind and McKoy 2016).

However, at the level of policy, the most recent calls for radical change in the tertiary sector have put cultural diversity as a central pillar of a new vision for music education. Sarath, Myers and Campbell's Manifesto for Progressive Change (2017), targeted at undergraduate music courses in the USA, draws both musical and social arguments for diversity together into a vision of ambitious scope. It is argued that a thorough knowledge of different musics of the world would give students the ability to grapple with sameness and difference by, on the one hand, experiencing music at a common perceptual level of 'sonic structures' (Sarath et al. 2017, p. 425) whilst also learning about specific cultural contexts. The purpose of diversity here is both transformative and compensatory, for instance, in drawing upon improvisation traditions to bring about a shift from interpretation to creation as the basis for musical engagement and at the same time to increase access of minorities to music higher education.

Further recent developments in the debates over diversity have sought to shift the centre of debate away from curriculum. Fears have been voiced that additive approaches to curriculum can result in tokenism, with poorly understood or integrated new content acting as a smoke screen for a more politically ambivalent praxis (Sharma 2004). In addition, this approach has been open to hijack from multiculturalists insistent on entrenching a rigid identity politics through curriculum

\footnotetext{
${ }^{2}$ Examples taken from a selection of UK conservatoires: Royal Conservatoire of Scotland's BA and MA courses in Scottish traditional and folk music; Royal Academy of Music's MA in Musical Theatre performance.
} 
(Karlsen et al. 2016). Looking instead at the efficacy of pedagogical processes through 'culturally responsive teaching' (Gay 2018), Lind and McKoy (2016) make the case that music's close connection to culture and personal identity requires teachers to be aware of the elements of cultural socialization that most directly concern learning in the classroom. However, they also acknowledge that 'the path to greater understanding is challenging; remedies are not readily apparent and the topic is sensitive in nature' (McKoy et al. 2009, p. 52).

This account of existing debates in the music education literature has shown that school music has received more attention in the literature and made more changes in practice than conservatoires in both curriculum content and pedagogy in response to the need to engage with cultural diversity. To open up a rationale to problematize the teaching of international students in the conservatoire, I now turn to the literature on higher education that critiques internationalization at the level of institutional policy and, in turn, how these critiques affect international students in teaching.

\section{Internationalization in Higher Education: Policy and Pedagogy}

International students are coming to study at Western institutions in increasing numbers; however, there is a growing disquiet with the shortcomings of the perceived dominance of an economic discourse. Critiques have existed for a number of years now that argue that in policy internationalization has only been crudely enacted as a drive to bring more people into campuses (Robson 2011). More recently, Haapakoski and Pashby's inquiry into policies behind the increase of international student numbers in Western higher education found that economic factors were cited most often in policy directives. When civic benefits were mentioned, these too were with recourse to discourses of economic benefit for host countries (2017). This has fuelled fears that higher education is being reduced to a predominantly commercial enterprise that could also work to reproduce global inequalities in the absence of questioning 'the assumptions behind who benefits from [higher education] and internationalisation and how' (Haapakoski and Pashby 2017, p. 361).

These concerns might seem exaggerated given that diversity is often overtly celebrated in the discourse of higher education. Even beyond this generalized approval, research shows tangible benefits are made available to all students in ethnically diverse education communities. Gurin et al. (2002) show that higher education coincides with a sensitive period in young people's identity formation and that peer influence forms a major part of how individuals construct themselves in relation to the socio-political world. A diverse student body therefore gives rise to tolerant and worldly graduates. Via Piaget, Gurin et al. argue that diverse communities bring with them discontinuity and discrepancy that 'spur cognitive growth' (2002, p. 335) across the wider student population. However, whilst 
there is broad agreement that engaging with 'cross-cultural ignorance' (Singh 2009, p. 185) can enable intellectual development, in practice this does not happen. Expressions of diversity are usually limited to the general environment of an institution, whilst the stuff of teaching and learning remains unaltered.

This suggests that host institutions are failing to maximize the benefits of internationalization. What, however, might be the effects of this restricted vision on international students themselves? The emergence of a sizeable literature on specific pedagogies for international students would perhaps suggest that when asked to learn solely within the frames of reference of the host institution, problems do arise. For instance, one such popular resource for teachers that coincided with the rise of internationalism in higher education (Biggs 2003) described three phases that teachers would go through in attempting to negotiate cultural divides in the classroom. The first two phases were described in terms of a deficit; by holding up host countries' often tacitly expressed educational values as a norm, international students were seen as lacking. Whilst phase one hoped that students would assimilate themselves into the new way of doing things, phase two typically involved the teacher accommodating difference by adopting new and creative teaching techniques to 'plug gaps' in perceived holes in student knowledge or behaviour. The third stage was called 'education', where the focus returned to the students but this time within the larger context of the student's educational experiences and cultural frames of reference in which prior learning had taken place (Biggs 2003, p. 133).

The desired conceptual shift for teachers is that once the wider context of learning was taken into account, differences that were once attributed to a characteristic of race, for instance, being passive and uncritical, unwilling to participate in class discussions and relying on rote learning (Biggs 2003) would now come to be located somewhere different, as part of another cultural perspective rather than a fixed attitude or property of cognition. Akin to culturally responsive teaching (Gay 2018), Biggs (2003) revealed these stereotypes as myths that dissolved once the teacher worked out which cultural understandings underpinned the behaviour and then skilfully directed students to reach the intended goal. Thus, once a wider context was taken into account, good teaching could give a level playing field to all students.

\section{Constructing Diversity in the Conservatoire}

To what extent are attempts made to negotiate the wider context of learning of international students in Western classical music? I will now look at two examples from the research literature that articulate teachers' points of view, coming from a Western perspective, of teaching Chinese students. Esslin-Peard and Shorrocks (2017) write of a university music programme in the UK with a high number of international students from China, whilst Huang and Thibodeaux (2016) come from faculties of music in the USA and write of the masterclasses they give to Chinese students in summer programmes in China. Both accounts give the wider cultural 
context of music students in China, explaining that the study of classical music is often chosen as an accomplishment that can be seen to improve status in society and to advance through to prestigious schools and higher education. As such, visible markers of success such as competitions, and the need for the technical brilliance that goes with them, play an important role in students' aspirations.

In terms of taking into account the wider cultural context, both articles describe effort and rote learning, along with deference to instrumental teachers as originating in students' enculturated values of Confucianism. In their accounts, both sets of teachers are in accordance with Biggs' advice to look at what students might do to achieve desired results. Esslin-Peard and Shorrocks use reflective writing, an often advocated tool in Western teaching (Boud 2010), and ask whether Chinese students approach these with the critical outlook needed to provoke the necessary change in learning. Huang and Thibodeaux try a range of interventions, including educating about European music history and composers. Further strategies are aimed at prompting Chinese students to break free of performing 'woodenly by rote' and instead direct them to 'thoughtful engagement with the music' and 'depiction of detailed emotional content' (2016, p. 30).

What is notable here is that these results are always discussed within implicit frames of Western values, from expectations around being critical to what counts as emotional engagement, musical understanding and, perhaps more fundamentally, being musical. Thus, even when attempting to teach in a culturally sensitive manner as per Biggs, whilst the goal is a fixed notion of what counts as right by Western standards, teaching can only ever be enacted as transmitting a set of norms of the host culture. Students who do not assimilate are understood as stereotypes, fixed by explanations to common culture (on both sides), so that Chinese students are always positioned as being 'in need' of a Western education.

With this bleak reading, Haapakoski and Pashby's plea that we look at 'the assumptions behind who benefits from [higher education] and internationalisation and how' (2017, p. 361) would seem timely. Undoubtedly, there is general approval on the ground for a culturally diverse student body, but does this go beyond surface expressions of a politically correct multiculturalism, the hubris of publicizing a conservatoire's 'world-class' status, or, taking steps to manage practical difficulties that arise by, for instance, providing extra language support? It would seem that without a clear sense of articulating what international students can bring beyond fulfilling admissions quotas and fees targets, conservatoires can suffer from the same charge of economic exploitation that Haapakoski and Pashby bring to the rest of higher education. 


\section{From (Containing) Cultural Diversity to (Playing with) Cultural Difference}

I would like to suggest that Bhabha (1994), by merging colonial theory's concerns with how colonizers subjugate the colonized with post-structuralism's focus on the contextual and mutable nature of meaning, offers some useful ways for mapping out a space in which to make sense of and move through these observations. Like theorists such as Said (1978) before him, Bhabha looks at how stereotypes and identities are constructed within colonizer-colonized roles and how they enforce cultural supremacy. However, a key difference to his predecessors is that for Bhabha the mechanisms of cultural superiority, rather than working to produce clear-cut and fixed categories, are constantly relational, with colonizer and colonized implicated and imbricated within each other through a co-existing process of attraction and repulsion. This produces an ambivalence that works against conceptions of identity that are essentialist and explanations which are consistent and whole (Andreotti 2011).

In terms of thinking through China's relation with Western classical music admiring but also with a motivation to demonstrate strength through engaging and perhaps even outdoing Western performance standards of classical music (see Huang 2012) - Bhabha's concept of ambivalence, suspending both attraction and repulsion simultaneously, has resonance. This is also seen in the rationale behind conservatoire recruitment strategies; after all, the decision to recruit heavily from China, as well as fulfilling economic need, is also made by way of arguing that Chinese students meet or exceed a certain standard. By possessing attributes, e.g. technical accomplishment and exemplary work ethic, they are chosen by audition panels in preference to their Western counterparts. This approval in recruitment also gives an endorsing sense of Western classical music's universal appeal and significance to those doing the recruiting. However, it can seem contradictory when seen to co-exist with the propensity to invoke marginalizing stereotypes once students have arrived.

As tools of understanding this uneasy relationship, two more concepts from Bhabha may be helpful: mimicry and stereotypes. The urge on the part of the colonizer to make the colonized reproduce its own culture, assumptions and values leads to what Bhabha calls mimicry. As something that is 'almost the same, but not quite', mimicry is always met with fear that to recognize the colonized as the same as the colonizer would erode the colonizers' sense of superiority which justifies domination. Thus 'it is at once resemblance and menace' (Bhabha 1994, p. 86). To cope with the fear of mimicry, colonizers resort to creating stereotypes, constructions of Otherness with fixed identities that characterize the colonized as 'knowable, unchangeable, and predictable' (Andreotti 2011, p. 26). The approval shown at recruitment stage as culture, assumptions and values are (nearly) replicated, later turns to the need to contain rather than engage with the Other, and this is done by recourse to stock Asian stereotypes. 
How do we navigate away from this impasse? Bhabha suggests that the problem lies with our tendency to conceptualize cultural diversity as something fixed and knowable (2006). Hidden inside the notion of cultural diversity is an assumption that identities are stable according to ethnicity and that cultural concepts and customs are pregiven because of race (e.g. because of Confucian beliefs, all Chinese students will approach Western classical music in a given way/ people who come from the West will engage on an emotional level with music in a certain way). Bhabha argues that cultural diversity (2006) is conceptualized so that stories of common history, background and traditions all rely on verifying and proving links to origins to maintain their credibility. Perhaps unexpectedly, Bhabha also critiques universalism as flawed by the same logic, so that certain characteristics occur because we are all supposedly members of 'mankind'.

Stories of origins and 'fixity' (Andreotti 2011, p. 26) are problematic for Bhabha as they conceal the fact that peoples have always intermingled and there is no such thing as racial purity. By extension culture has been, and remains as a result of this intermingling, perpetually hybrid. This notion is crucial in reversing claims of dominance, as seeing hybridity in all cultural forms and meanings enables us to reject narratives which cast certain peoples as legitimate inheritors or sole carriers of traditions.

But, to Bhabha, culture is also fluid and unknowable in a further more basic sense as he sees language as necessarily ambivalent, even at its point of enunciation, 'it is only when we understand that all cultural statements and systems are constructed in this contradictory and ambivalent space of enunciation, that we begin to understand why hierarchical claims to the inherent originality or 'purity' of cultures are untenable, even before we resort to empirical historical instances that demonstrate their hybridity' (Bhabha 2006, pp. 156-157). By moving from cultural diversity to cultural difference, Bhabha exploits this lack of common ground by suggesting that a truly international meaning can emerge in a third space of, 'the 'inter'-..., the in-between... that carries the burden of the meaning of culture.... It is in this space that we will find those words with which we can speak of Ourselves and Others. And by exploring this hybridity, this 'Third Space,' we may elude the politics of polarity and emerge as the others of our selves' (2006, p. 157).

How might these concepts be used to imagine and bring about alternative futures for international students in conservatoires, futures that 'elude the politics of polarity'? A key move would be to use the concept of hybridity as the basis to disrupt the authority by which those in conservatoires fix meaning, standards and norms, exposing the fabrication upon which Western classical music is said to belong to one group of people and not another. That would put the onus on teachers to move from being inheritors/guardians of traditions that can draw lineage back through generations of previous teachers to a supposedly identifiable origin. Instead teaching would become an act of facilitating the decolonization of knowledge and culture in a 'third space'.

In contrast to concepts of cultural exchange which all too easily can reduce to discussions of 'norm and Other' ('We do things here like this; oh, you do things over there like that...?'), the third space offers a neutral forum where discourses can be 
mediated, navigated between or imagined anew. Students can be given the chance to rewrite their narratives rather than be forced to live by the ones imposed upon them, negotiate local and global contexts and compare disciplinary knowledge and lived experience. Such an education would also give students a chance to make relevant a Western curriculum to their own personal and geographical contexts and, by refusing to marginalize in the face of difference, would be more ethically just.

Though this might seem fanciful when viewed through the lens of conservatoire realpolitik, it is of note that precedent already exists in graduate professional training to explicitly set up third spaces for students to navigate different and potentially contradictory domains, for instance, disciplinary and professional knowledge (e.g. Tremonte 2011). Music, arguably prone to more ambivalence in meaning than language, would be ripe for experiment and discussion in a third space that could bring the identity of the performer into dialogue with performance traditions. Furthermore, in Bhabha's definition of mimicry, based around the colonized's ultimately failed attempt to mimic the colonizer, there seems to be an additional resonance with classical music; to what extent are all attempts of interpretation acts of mimicry, more so in classical music than in other performance arts because of the dictum that through our performance we aim to 'recreate the composer's' intentions'? Could all performance students explore their relationship to mimicry through entering into a third space that would allow them to bring their personal identities, histories, qualities and neurodivergences into collision with the traditions and performance lineages of the works they perform? This example diffuses the unhelpful perpetuation of groups of colonizer and colonized and also takes up Bhahba's invitation to 'emerge as the others of our selves' (2006, p. 157). Stated thus more broadly, this is potentially liberating for all conservatoire students and promises a renewal of classical music that many contemporary commentators point to as a necessary condition of avoiding its obsolescence (e.g. Leech-Wilkinson 2016).

Ultimately, each institution would have to find its own platform for students to engage with learning in a third space. Though the relinquishing of traditional lines of authority in the conservatoire might seem unlikely, enabling cultural difference to be at the centre of teaching and learning would avoid the troubling prophecy that internationalization can only ever lead to economic exploitation via a marginalization of the very students it seeks to recruit. By actively engaging with difference, conservatoires could fully deliver on their duty of care to international students. At the same time, they would transform themselves from sites of cultural reproduction based on a Western norm to a more student-centred education - a move that would surely benefit all conservatoire students. 


\section{References}

Andreotti, V. (2011). Actionable postcolonial theory in education. New York: Palgrave Macmillan. Barenboim, D. (2016). https://www.facebook.com/danielbarenboim/posts/981547811916027. Accessed May 102019.

Bhabha, H. K. (1994). The location of culture. London: Routledge.

Bhabha, H. K. (2006). Cultural diversity and cultural differences. In B. Ashcroft, G. Griffiths, \& H. Tiffin (Eds.), The post-colonial studies reader (pp. 155-157). New York: Routledge.

Biggs, J. B. (2003). Teaching for quality learning at university: What the student does (2nd ed.). Buckingham: SRHE \& Open University Press.

Boud, D. (2010). Relocating reflection in the context of practice. In H. Bradbury, N. Frost, S. Kilminster, \& M. Zukas (Eds.), Beyond reflective practice (pp. 25-36). Abingdon: Routledge.

Citron, M. (1993). Gender and the musical canon. Urbana and Chicago: University of Illinois Press.

Drummond, J. (2005). Cultural diversity in music education: Why bother? In P. Campbell, J. Drummond, P. Dunbar-Hall, K. Howard, H. Schippers, \& T. Wiggins (Eds.), Cultural diversity in music education: Directions and challenges for the 21st century (pp. 1-13). Australian Academic Press: Bowen Hills.

Esslin-Peard, M., \& Shorrocks, T. (2017). Using reflection to develop insights into musical practice and performance: A pilot study with Chinese M Mus students. Paper presented at the Musical Cultures Conference/SEMPRE Conference Proceedings, Hull, April 2007. http://livrepository. liverpool.ac.uk/id/eprint/3014957.

Ford, B. (2010). What are conservatoires for? Discourses of purpose in the contemporary conservatoire (Doctoral thesis). Retrieved from UCL Discovery database http://discovery.ucl.ac.uk/ 10007379/. Accessed 14 July 2020.

Gay, G. (2018). Culturally responsive teaching: Theory, research, and practice (3rd ed.). New York: Teachers College Press.

Goehr, L. (1992). The imaginary museum of musical works: An essay in the philosophy of music. Oxford: Oxford University Press.

Gurin, P., Dey, E., Hurtado, S., \& Gurin, G. (2002). Diversity and higher education: Theory and impact on educational outcomes. Harvard Educational Review, 72, 330-365.

Haapakoski, J., \& Pashby, K. (2017). Implications for equity and diversity of increasing international student numbers in European universities: Policies and practice in four national contexts. Policy Futures in Education, 15(3), 360-379.

Ho, W.-C. (2018). Culture, music, education, and the Chinese dream in mainland China. Singapore: Springer.

Huang, H. (2012). Why Chinese people play western classical music: Transcultural roots of music philosophy. International Journal of Music Education, 30(2), 161-176.

Huang, H., \& Thibodeaux, T. (2016). Teaching piano in China: Building transcultural and transhistorical bridges through music education. International Research in Higher Education, 1(2), 25-33.

Karlsen, S., Westerlund, H., \& Miettinen, L. (2016). Intercultural practice as research in higher education: The imperative of an ethics-based rationale. In P. Burnard, E. MacKinlay, \& K. Powell (Eds.), The Routledge international handbook of intercultural arts research (pp. 369-379). Abingdon/New York: Routledge.

Leech-Wilkinson, D. (2016). Classical music as enforced utopia. Arts and Humanities in Higher Education, 15(3-4), 325-336.

Lind, V. R., \& McKoy, C. (2016). Culturally responsive teaching in music education: From understanding to application. New York: Routledge.

McKoy, C. L., Butler, A., \& Lind, V. R. (2009). Conceptually framing music teaching and learning within the context of culture: Implications for music teacher education. In M. Schmidt (Ed.), Collaborative action for change: Selected proceedings from the 2007 Symposium on Music Teacher Education (pp. 20-51). Lanham, MD: Rowman \& Littlefield. 
Robson, S. (2011). Internationalization: A transformative agenda for higher education? Teachers and Teaching: Theory and Practice, 17(6), 619-630.

Said, E. (1978). Orientalism. London: Routledge and Keegan Paul Ltd..

Sarath, E., Myers, D., \& Campbell, P. (2017). Redefining music studies in an age of change: Creativity, diversity, and integration. New York: Routledge.

Schippers, H. (2010). Facing the music: Shaping music education from a global perspective. Oxford: Oxford University Press.

Schopenhauer, A. (1818/1966). The world as will and representation (Vols. 1-2, E. F. J. Payne, Trans.). New York: Dover.

Sharma, S. (2004). Transforming the curriculum? The problem with multiculturalism. In I. Law, D. Philips, \& L. Turney (Eds.), Institutional racism in higher education (pp. 105-118). Stoke on Trent: Trentham Books.

Singh, M. (2009). Using Chinese knowledge in internationalising research education: Jacques Ranciere, an ignorant supervisor and doctoral students from China. Globalisation, Societies and Education, 7(2), 185-201. https://doi.org/10.1080/14767720902908034.

Tremonte, C. (2011). Cartographies: Graduate education, SOTL and the third space. Arts and Humanities in Higher Education, 11(4), 387-405.

Universities UK. (2017). International students now worth $£ 25$ billion to UK economy - new research. Accessed 21 Nov 2019, from https://www.universitiesuk.ac.uk/news/Pages/ International-students-now-worth-25-billion-to-UK-economy\%2D\%2D-new-research.aspx.

Wang, Y. (2019). Finding my voice: An interdisciplinary and multi-methodological investigation into the relationship between performers' speech and musical expression. [DMus thesis, Guildhall School of Music \& Drama: City University].

Biranda Ford is Graduate Research Training and Development Leader at the Guildhall School of Music \& Drama, where she teaches on the doctoral programme. She studied music at Oxford University, violin at San Francisco Conservatory of Music and completed her PhD at the Institute of Education, London. Her research interests centre around music education, including pedagogy, intercultural learning and decolonizing higher education.

Open Access This chapter is licensed under the terms of the Creative Commons Attribution 4.0 International License (http://creativecommons.org/licenses/by/4.0/), which permits use, sharing, adaptation, distribution and reproduction in any medium or format, as long as you give appropriate credit to the original author(s) and the source, provide a link to the Creative Commons license and indicate if changes were made.

The images or other third party material in this chapter are included in the chapter's Creative Commons license, unless indicated otherwise in a credit line to the material. If material is not included in the chapter's Creative Commons license and your intended use is not permitted by statutory regulation or exceeds the permitted use, you will need to obtain permission directly from the copyright holder.

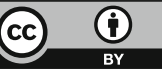

